\title{
A Low-Cost Launch Assistance System for Orbital Launch Vehicles
}

\author{
Oleg Nizhnik \\ ERATO Maenaka Human-Sensing Fusion Project, 8111, Shosha 2167, Hyogo-ken, Himeji-shi, Japan \\ Correspondence should be addressed to Oleg Nizhnik, oleg@eratokm.jp
}

Received 17 February 2012; Revised 6 April 2012; Accepted 16 April 2012

Academic Editor: Kenneth M. Sobel

Copyright (C) 2012 Oleg Nizhnik. This is an open access article distributed under the Creative Commons Attribution License, which permits unrestricted use, distribution, and reproduction in any medium, provided the original work is properly cited.

\begin{abstract}
The author reviews the state of art of nonrocket launch assistance systems (LASs) for spaceflight focusing on air launch options. The author proposes an alternative technologically feasible LAS based on a combination of approaches: air launch, high-altitude balloon, and tethered LAS. Proposed LAS can be implemented with the existing off-the-shelf hardware delivering $7 \mathrm{~kg}$ to low-earth orbit for the 5200 USD per kg. Proposed design can deliver larger reduction in price and larger orbital payloads with the future advances in the aerostats, ropes, electrical motors, and terrestrial power networks.
\end{abstract}

\section{Introduction}

Spaceflight is the mature engineering discipline- 54 years old as of 2012. But seemingly paradoxically, it still relies solely on the hardware and methodology developed in the very beginning of the spaceflight era. Modernly, still heavily-used Soyuz launch vehicle systems (LVSs) are the evolutionary improvement of the R-7 rocket which launched the very first Sputnik satellite. Although many advanced rocket concepts were proposed and even implemented (most notably the Space Shuttle), these designs did not stand the test of the time. The comprehensive review on the current state of art in field of rocket propulsion can be found in [1] Nonrocket-based spaceflight was also heavily researched, but the research did not result in practical systems other than the Pegasus LVS which is scheduled for retirement. The main reason why nonrocket spaceflight schemes were not widely implemented yet is their failure to compete with the purely rocket spaceflight schemes in the field of the orbital delivery of the high-value payloads like communication satellites or interplanetary probes. But baseline rocket cost denies many less valuable yet desirable payload classes like orbital power or industrial plants or machinery for extraterrestrial resources utilization. To ultimately enable these payload classes, an interim prototype of the nonrocket launch assistance system (LAS) should be developed to launch experimental payloads. Therefore, an economically viable systemlevel design of the LAS delivered in this paper may be key point to the progress in the orbital delivery systems for these additional payload classes.

\section{Overview of Previously Proposed LAS}

A lot of proposals have been made to implement nonrocket LAS and are listed in Table 1.

The Rumanian Space Agency/ARCASPACE [2] has proposed to launch a moon probe from a high-altitude balloon. If the rocket start altitude of $20 \mathrm{~km}$ can be reached, a very light-weight, cheap launch vehicle may be possible. However, at the $20 \mathrm{~km}$ altitude, each ton of the rocket needs at least $200,000 \mathrm{~m}^{3}$ for the volume of the solar-heated Montgolfier balloon as proposed by ARCASPACE. So the design of an ultrahigh-altitude ARCASPACE balloon is expensive and technically challenging task. Furthermore, such a huge balloon is expendable, and the long ascent time requires usage of storable propellants in the rocket. Also, ARCASPACE balloons can be launched only in sunny weather, implying delay costs. Finally, their position during the launch is uncertain, complicating the safety area.

The electromagnetic launchers (railguns) for accelerating a small payload from LEO were also proposed [3] in the wake of the SDI program. But the railgun is an intrinsically very high-power device $(30-1000 \mathrm{TW}$ in proposed configurations). Such power levels impose weight penalties for the structural and energy storage materials, as well as the distribution and dissipation elements, making orbital 
TABLE 1: Previously proposed launch assistance systems.

\begin{tabular}{lc}
\hline Method & References \\
\hline High-altitude free-floating Montgolfier balloon & {$[2]$} \\
Orbital electromagnetic catapult & {$[3]$} \\
Laser ablation drive & {$[4-6]$} \\
Space elevator & {$[7,8]$} \\
LEO rotovator & {$[9-11,13]$} \\
Spiral sling (slingatron) & {$[14-18]$} \\
Interplanetary rotating tethers & {$[19-29]$} \\
Rotating, tension supported ring & {$[30]$} \\
Electromagnetic tether for raising orbit & {$[31-33]$} \\
Space fountain & {$[34]$} \\
Ground-based linear accelerator (gun, catapult) & {$[36-39]$} \\
Subsonic launcher aircraft & {$[40,94]$} \\
Precooled air ramjet launcher aircraft & {$[42,43]$} \\
Supersonic launcher aircraft in general & {$[41,44]$} \\
\hline
\end{tabular}

railguns uneconomic. Railgun devices in [3] are capable of launching $0.3 \mathrm{~kg}$ payloads with speeds $4-10 \mathrm{~km} / \mathrm{s}$ (realistic with existing technology), but the launcher itself is likely to weigh more than 300 tons (because at least 200 tons are needed for capacitors alone), with a 5,000-ton weight being a more likely estimate.

An initial proposal for a rocket engine based on the heating of propellant by remote laser was made in [4]. But given the low continuous power of available lasers (below $1 \mathrm{MW}$ level) and bad transmission efficiency, such propulsion method requires many improvements in laser technology beyond the current level. In [5] the power requirement for beamed-energy propulsion from Earth to orbit is estimated to be $0.1-1 \mathrm{GW}$ of continuous beam power per ton of the vehicle mass, which is 3-4 orders of magnitude higher than current state-of-art laser transmitters. As a consequence, the best altitude reached by a beamed-energy aircraft in 2001 was only $71 \mathrm{~m} \mathrm{[6].} \mathrm{Space} \mathrm{elevator} \mathrm{system} \mathrm{is} \mathrm{perceived} \mathrm{a} \mathrm{viable}$ solution [7] but it is far from being possible with the current material technology [8].

Rotating tether systems $[9,10]$ can be useful for the reduction of the delta-v from earth's surface to orbit. But the required spaceship guidance accuracy to enable rendezvous with the rotating tether tip is higher than the task guiding an antisatellite missile and cannot be performed reliably with current guidance technology. Normal rocket LVSs are not agile enough for the last-second speed vector adjustments. In [11] a more robust rendezvous method using a motorized grapple was proposed. It has the advantage that a highagility engine system is placed on the tether grapple; thus extensive redesign of the rocket LVS propulsion system is not necessary. But for a practical rendezvous time window of 10 seconds with a realistic $25 \mathrm{~km}$ long, $1.6 \mathrm{~km} / \mathrm{s}$ tip speed tether, a rendezvous motor must provide a delta-v of at least $500 \mathrm{~m} / \mathrm{s}$ for compensating the lateral mismatches. The grapple also must include a $50 \mathrm{~kW}$ power motor per $1 \mathrm{~kg}$ of grapple weight to wind/unwind the tether to compensate radial mismatches. This power ratio is 2 orders of magnitude above what is achievable with the best industrial-grade electric motors [12]. Using a chemical-fuel powered turbine for the winding/unwinding may solve the weight issue, but in this case some reaction mass must be spent for radial grapple adjustments as well. Because the power requirements for rendezvous scale as reverse square of tether length, making a realistic motorized-grapple tether rendezvous system with 10 seconds rendezvous window thus requires tethers at least $100 \mathrm{~km}$ long. A possible solution for the tether tip rendezvous problem was proposed in [13]. The additional actuator mass necessary to reduce the acceleration of tether tip during the rendezvous places additional strain on tether, causing reduction in either captured payload mass or tether tip speed.

In [14-17] the spiral sling was proposed. That structure does not address the problem of the multigigawatt electrical power required to drive the sling carrying a projectile heavy enough to fly out of the Earth's atmosphere. The smallest slingatron LASs comprise a 2700-ton track $90 \mathrm{~km}$ long moving at $139 \mathrm{~m} / \mathrm{s}$ [18]. Such system is heavier, faster, larger, and more power hungry and has order-of-magnitude higher acceleration than the largest bullet trains ever built.

Kevlar tethers were proposed in [19] as the effective means of orbit change. The figure of merit (1) of the tether used for this purpose was derived:

$$
v_{\text {tip }}=\sqrt{2 \cdot \delta \cdot \frac{E}{\rho}},
$$

where $v_{\text {tip }}$ is the maximal speed of the unloaded, untapered tether tip fixed on one end, $\delta$ is the elongation to break the tether, $E$ is the Young modulus of the tether material, and $\rho$ is the density of the tether. Although [19] overstates the maximal tether tip speed (1) by a factor of 10, their theoretical analysis is valid and was used to select a proper tether (rope) material. Reference [20] proposed a sensible construction to safely couple a motor with a small-diameter tether. That belt transmission-based design does subject the tether to a well-controlled and self-limiting stress, a valuable property for a system with a small safety factor. In [21] rotating tethers were proposed for Earth-Moon transportation. Spectre 2000 (a brand of UHMWPE) was proposed for tether fabrication. The required high speed of the tether tip $(1.6 \mathrm{~km} / \mathrm{s})$ on lunar orbit makes the tether system 28 times heavier than payload; therefore at least 100 reuses of the tether are necessary to payoff tether deployment. Better tether materials may reduce the capital costs of the systems depicted in [21]. Tethers could also be used for swinging about asteroids [22] without spending propellant. Reference [23] also proposes to use Spectra 2000 tethers for orbital transfer (without engineering analysis). The usage of the tether to capture a payload in planetary orbit while the mothership of the payload performs a flyby maneuver was proposed in [24-26]. To be competitive with state-ofart chemical propulsion, the speed change of the payload is limited to $0.3 \mathrm{~km} / \mathrm{s}$. Tethers were also proposed to transport cargo between Mars and Earth [27], but the low strength of existing materials made the tethers too heavy to compete with rocket propulsion. In [28] guidance to the tether rendezvous was discussed. The conclusion was the statement 
of absence of the means to prolong the rendezvous interval long enough to enable capture of payload on rotating tether tip. The usage of tethers to provide an abort option for Mars travel was proposed in [29]. With typical delta-v below $1 \mathrm{~km} / \mathrm{s}$, a practical tether can be developed. However given the mass constraints of Mars travel, the implementation of the abort capability is unlikely.

A variation of the tether concept, a rotating rim on LEO, was proposed in [30] as LAS implementation. This design allows for easier attachment of spacecrafts, because a continuous attachment line requires less delta-v and acceleration to compensate for guidance errors compared to grapple. Design in [30] demands a material with $v_{\text {tip }}$ being $\sqrt{2 \pi}$ times more than that of a conventional rotovator.

In [31] methods to raise a satellite into orbit using an electromagnetic tether were proposed. But to reach orbit, the apogee of the tether-bearing spacecraft must be above geostationary orbit, and possible acceleration is small. Reference [32] also has proposed a method to extract energy from space plasma using an electromagnetic tether. But this method works only in zones near Lagrange points. Reference [33] also proposes using rotating tethers coupled to the Earth's magnetosphere to change the spacecraft's orbit. Rotating the tether increases tether rigidity, making orbital control more simple compared to a hanging or librating tether.

In [34] a reasonable downscaling method of a space fountain is proposed. But even a small-scale $(2.5 \mathrm{~km} / \mathrm{s}, 1-$ pipe space fountain) system has an upkeep power of $16 \mathrm{GW}$ (2/3 of the electricity produced by Japan), a 56-ton weight suspended in atmosphere (likely more if control and safety devises added), a stored kinetic energy 120 GJ (22 tons TNT equivalent), and a $150 \mathrm{~km}$ long building footprint. LAS in [34] features $190 \mathrm{~km}$ long pipe span under tension that may be difficult to build using existing materials. Furthermore, the 1.5 billion USD miniature space fountain building budget in [34] is including only materials costs. Upkeep power generators alone (the cheapest option-gas turbine) [35] are expected to cost 6.4 billion USD to build.

Potential economic advantages of ground-based catapults are listed in [36], but a $4 \mathrm{GW}$ average power system with the $100 \mathrm{GJ}$ local energy storage proposed does require a specialized power station. In [37], the vacuum launch tube for small sounding rockets was proposed. Although the design allows for a 10-20\% increase of the sounding rocket altitude, the 23.5-meter-long semi-rigid launch tube makes the design uneconomical. Slightly oversizing a 2 -meter-long rocket with much smaller fabrication and handling difficulty allows it to reach the same maximal altitude. In [38] a pneumatic sled was proposed as LAS for the orbital vehicle. That LAS is analogous to existing steam catapult used aboard of the US supercarriers. These catapults are known to have an issue with the high cost of maintenance, which is the primary reason for their applications being restricted to launching military airplanes.

Another proposed method of launch assistance is shooting the launch vehicle with high-caliber, high-explosive, ultravelocity shells at machine-gun speeds [39]. Launch vehicle must survive $\sim 10,000$ such impacts, each delivering 10 100 times more kinetic energy compared to the largest modern gun projectiles at $\sim 10$ collisions/s. Reference [40] proposes a solution for an air launch system based on exotic propellant chemistry. Reference [41] finds that the delta- $v$ advantage of launching from $30 \mathrm{~km}$ altitude is $700 \mathrm{~m} / \mathrm{s}$ and optimal angle between launch angle and horizontal is close to $30 \%$, while vertical launch from $30 \mathrm{~km}$ altitude gives $500 \mathrm{~m} / \mathrm{s}$ delta-v reduction to reach the LEO.

Among the huge body of the literature discussing airbreathing engines for LVS, the author exhibits one solutiona precooled engine, to illustrate the technological challenges of the solution. In [42], the design of the air heat exchanger for an air-breathing vehicle similar to Skylon was elaborated. But the designs proposed have flow-to-weight ratio below $0.03 \mathrm{~s}^{-1}$ for 5.5 Mach speed, so the maximal thrust to weight of the heat exchanger is less than 10 for an exhaust speed of $3 \mathrm{~km} / \mathrm{s}$. In [43], a heat exchanger for the air precooler was designed using stainless steel tubes with $2 \mathrm{~mm}$ outer diameter and $0.1 \mathrm{~mm}$ wall thickness. These pipes will break in the 5.5Mach airflow if made more than $12 \mathrm{~cm}$ long. Furthermore, [43] assumes very light, advanced air-breathing engines. If a thrust to weight similar to the Pratt \& Whitney J58 engine can be achieved (which was designed for similar airspeed, but without precooler), the total engine's mass will be the $45 \%$ of the vehicle's 12 ton dry mass. With the payload mass fraction of $1.25 \%$ of the dry mass, the design still requires many advances in material technology before implementation.

In general, hypersonic launcher aircraft (LAS) plus LVS is more expensive [44] compared to purely rocket LVS, and the reasons for it being too expensive are elaborated in the next chapter.

\section{The Critic of the Air Launch Concept}

Among nonrocket LASs the high-altitude launch using carrier aircraft should be discussed in more detail, because Pegasus high-altitude launch with carrier aircraft was only LAS method implemented historically, and problems with Pegasus resulting in its planned retirement in favor of the landbased Taurus and Taurus XL rockets will shed the light on the peculiarities of the air-breathing LAS. To understand the motives beyond the Pegasus planned retirement let us first list advantages of the air launch.

References [40, 41, 45] estimate the delta-v saving due to using air launch to be $750 \mathrm{~m} / \mathrm{s}$ to $1000 \mathrm{~m} / \mathrm{s}$ for the subsonic carrier aircraft. This delta-v reduction translates to $28 \%$ rocket weight reduction for solid-fuel rocket or $19 \%$ rocket weight reduction for the LH2/LOX rocket according to rocket equation [46] have also reported $25 \%$ rocket dry weight reduction with the subsonic launcher aircraft carrying LOX/LH2 rocket. Air launch with carrier aircraft also has significant penalties listed below.

(1) Design compromises of the air-launched rocket, requirement for storable propellant, carrier aircraft crew safety [47], additional structural weight due to additional load direction of horizontally carried rocket [48], result in rocket weight reduction of only $15 \%$ out of maximal $28 \%$. 
(2) The second is effect of the capital and maintenance costs of aircraft, especially effect of engine power of carrier aircraft on flyaway cost. Reference [49] predicts whether higher-speed carrier aircrafts will be increasingly uneconomical as LAS. For example, Concorde [50] is predicted to have running costs $43 \%$ of equivalent expendable solid-rocket booster, and higher speed aircrafts (including all tentative scramjet designs) will be even less economical. Breakeven point with the solid rocket boosters is around Mach 3 for the current technology level. The authors of [44] have also concluded why hypersonic launcher aircraft cannot be economical despite significant delta-v savings for the carried rocket.

(3) The total cost of the orbital launch is dominated not by the flyaway cost. Instead R\&D amortization, certification, range safety, payload integration, and profit margin comprise up to $81 \%$ [51] of the launch costs. These costs reduce with the increasing launch rate and independent of launch technology.

To summarize, a classical air launch system fails to reduce the cost of LVS more than 3\% because air launch technology is subject to the same technological and procedural limitations as purely rocket LVS. This is not surprising given that space launch technology has grown mostly using an aircraft manufacture and service infrastructure.

\section{The Required Properties of the LAS}

Summarizing the data in chapters II-III, a list of the desired traits of the economical nonrocket LAS can be made.

(i) The power to operate must be deliverable by the modern power network on demand $(P<10 \mathrm{MW})$.

(ii) The mass of the airborne part of the LAS should be kept to minimum.

(iii) Local energy storage should be minimized (to avoid hazards of uncontrolled energy release).

(iv) Acceleration by LAS must be in same direction as by rocket engine (LVS must have only 1 structurally strong axis).

(v) Propulsive force by LAS must not exceed the force by equivalent rocket booster.

(vi) LAS-related hardware on board of LVS must be light.

(vii) No pilot aboard of airborne part of LAS is allowed.

(viii) LAS must deliver LVS to separation point promptly to use cryogenic fuels in the LVS.

(ix) Reusability of all components of LAS at least few times.

(x) Small launch turnaround time (no more than 1 day) to facilitate high launch rate.

(xi) Low payload mass to facilitate high launch rate.

(xii) Weather independence.

(xiii) Launch point and launch vector stability. (xiv) No high-acceleration rendezvous until much better guidance systems will be developed.

None of the proposals in sections II-III satisfy all criteria for the economical LAS. Therefore, an original proposal loosely based on the combination of the features of $[2,20,30]$ is described in chapter V. To summarize the most important principles, LAS must operate rapidly, at low power and low weight, meaning most likely low payload mass, and therefore a large starting altitude for the rocket to keep the air resistance loss reasonable same as what was aimed by the Orbital Sciences Corporation in their Pegasus project. No revolutionary breakthroughs are expected for rocket LVS itself. For example, [52] was written 20 years ago, and all perspective technologies listed within are still under development (except for the Li-Al alloys usage). To summarize, SSTO, ultralight rockets engines, air-breathing or rocket flyback boosters were not developed. The lack of rapid progress in the field was illustrated by the cancellation of the project RASCAL [53] aiming to reach the same goals using the purely rocket LVS. Therefore, the nonrocket LAS may be the only short-term path to the more economical, albeit small-scale, orbital delivery.

\section{Proposed LAS Concept}

Author's proposal calls for the high-altitude balloons cluster used as anchors for the cable traction system. The design parameters of the LAS/LVS are provided in Table 2. Tethered balloon is much easier to reuse compared to the floating balloon in [2]. Reuse of balloons is obligatory because these comprise the heaviest and most expensive component of the LAS. Also, the positioning of the tethered balloon can be precise to the fraction of meter [54]. Tethers (cables) connected to the high-altitude balloons can be used to accelerate an LVS if needed or simply to deliver launch vehicle to launch altitude before cryogenic propellants will boil off. Advantage of the tethered balloon over carrier aircraft system is the extreme simplicity of the flown hardware and advantageous initial speed vector for light payloads (vertical or nearly vertical).

To make the system a statically stable with only tensileloaded (and therefore lightest) spans, at least 3 balloons and 3 tethers (traction cables) arranged in axis-symmetric pattern are necessary. Balloons should be connected by clustering cable ( 2 on Figure 1 ) to set a stable small spacing between them. Static and dynamic load due the LVS being launched and tropospheric wind load acting on launch vehicle, cables, and balloons was calculated. Because the operational altitude of proposed balloon system is well above the top margin of the jet streams (at approximately $20 \mathrm{mBar}$ pressure while jet stream subsides above $90 \mathrm{mBar}$ level) [55], the jet stream winds affect only balloons during LAS deployment (there caution is necessary) and rocket LVS during launch. Because cables cross-section in jet stream zone and rocket LVS crosssection is small compared to the balloons, the jet stream load is insignificant to the LAS subsystem, although LVS still must withstand larger wind shears. The estimated $60 \mathrm{~m} / \mathrm{s}$ jet stream lateral force on LVS is $400 \mathrm{H}$, higher than the 


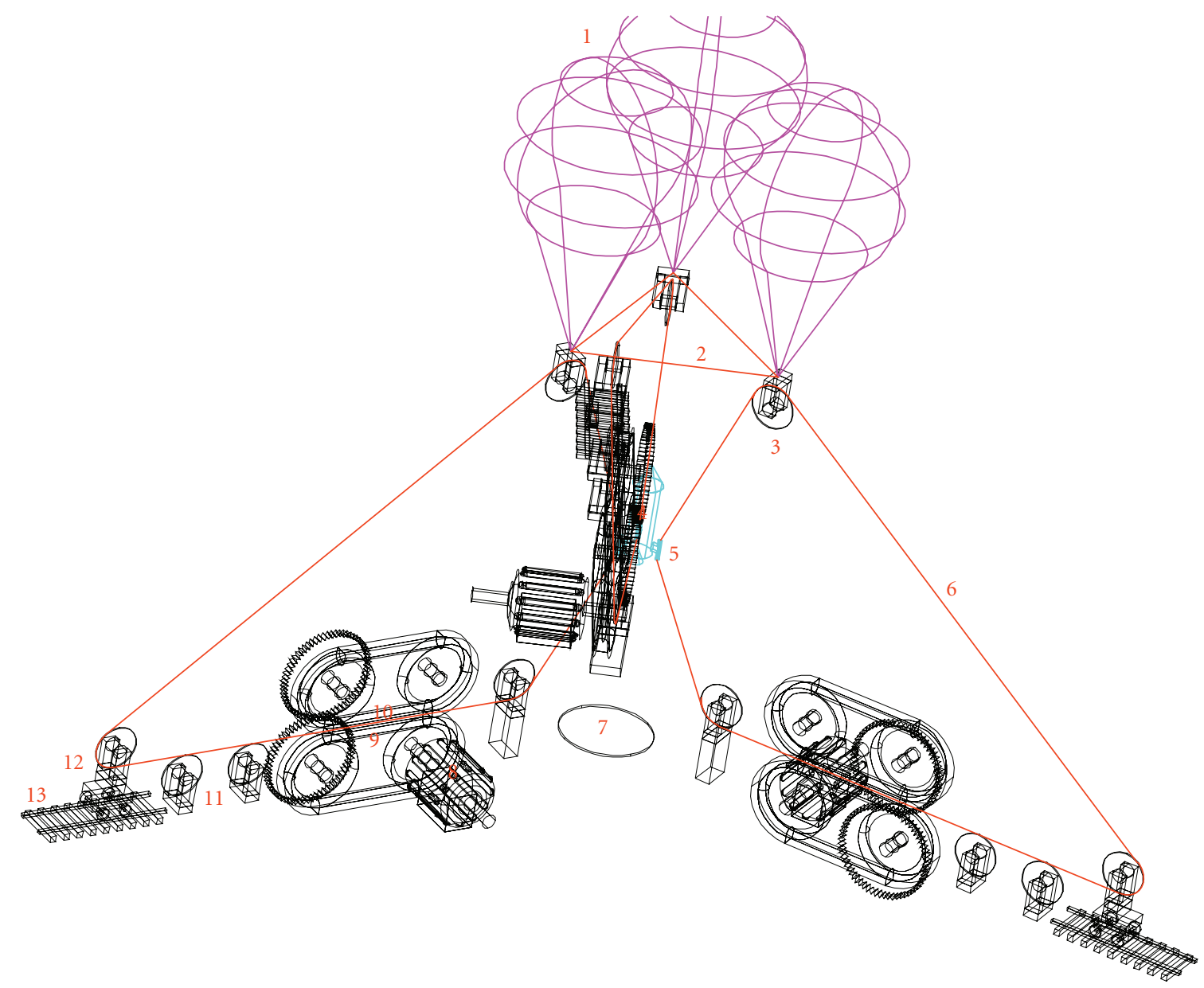

FIGURE 1: 3D model of the LAS (proportions distorted for clarity) (1): balloons, (2): clustering cable, (3): top block, (4): rocket LVS, (5): rocket attachment points to traction cables, (6): traction cables, (7): launch pad, (8): electric motors, (9): lower coupling belt, (10): upper coupling belt, (11): antisagging towers, (12): tension adjustment block, (13): rails for tension adjustment block.

rated ground-level wind load. But anyway the LAS/LVS design is not intended to withstand the jet stream loading because majority of the Earth surface including the most advantageous equatorial belt is not affected by the strong jet streams. The structural strength margin of 1.5 was selected for the entire LAS design to ensure survival of block bearings for at least 10000 loading cycles [56]. Angle between traction cables (5-3-12 on Figure 1) should be nonzero to effectively resist wind load on the balloons and ensure the repeatable launch vector. The larger the angle between the LVS rope (53 on Figure 1) and return rope (3-12 on Figure 1), the better rigidity of LAS can be achieved, but the return rope weight is also increased. Horizontal tether segment (12-7 on Figure 1) length was selected to be $7 \%$ of the balloons altitude, but depending on the land lot availability up to $30 \%$ may be advisable. The overview of the LAS/LVS parameters and the components breakdown of the LAS are provided in Tables 2 and 3 , respectively.

Overall, proposed LAS/LVS has weight and performance similar to the oldest Japanese launch vehicle Lambda-4S (9.4ton wet weight and $26 \mathrm{~kg}$ to LEO, resp.). But similarity ends here, because heaviest and most expensive components in the proposed system can be made reusable, as illustrated in Table 4.

The data in Tables 2-4 was generated using Microsoft Excel calculation sheets. Input data to the calculation sheets was derived from numerous datasheets (especially for onboard battery and power distribution subsystems), mass estimating relations [57], and from the output of the Scilab script used to simulate the ascent of the rocket to the LEO. The Scilab script was calibrated by simulating ascent of Proton-M, Delta 7920, Pegasus XL, H-IIA LVS. The calculation sheets and Scilab script are available on request.

In the current work it is not proposed to reuse the rocket LVS, because the potential advantages will not be decisive. References [58, 59] argue that reusable rocket LVS may be advisable only if launch demand is much increased compared to current level, which is unlikely according to [60]. The many capital costs of the LAS are order-of-magnitude approximations, but accuracy of these approximations does not matter as long as the ground part of the LAS can be reused 10000 times or more. Although such heavy reuse is not uncommon for the ground-based traction cable systems, the limiting factor is the demand 
TABLE 2: Parameters of the proposed LAS.

\begin{tabular}{|c|c|c|}
\hline \multicolumn{2}{|l|}{ Parameter } & Value \\
\hline \multicolumn{2}{|l|}{ Launched LVS weight } & $340 \mathrm{~kg}$ \\
\hline \multicolumn{2}{|l|}{ Payload to LEO } & $7 \mathrm{~kg}$ \\
\hline \multicolumn{2}{|l|}{ LAS engines output power } & 13.1 MW \\
\hline \multicolumn{2}{|c|}{ Balloons total volume } & $0.5 \mathrm{mln} \cdot \mathrm{m}^{3}$ \\
\hline \multicolumn{2}{|c|}{ Acceleration during launch assistance } & $5.7 \mathrm{~m} / \mathrm{c} 2$ \\
\hline \multicolumn{2}{|c|}{ Acceleration duration } & $161 \mathrm{sec}$ \\
\hline \multicolumn{2}{|l|}{ Separation airspeed } & $0.45 \mathrm{~km} / \mathrm{s}$ \\
\hline \multicolumn{2}{|l|}{ Separation altitude } & $36.1 \mathrm{~km}$ \\
\hline \multicolumn{2}{|c|}{$\begin{array}{l}\text { Flown structure weight (with ballast and launch } \\
\text { vehicle) }\end{array}$} & 8.6 tons \\
\hline \multicolumn{2}{|c|}{$\begin{array}{l}\text { Flown structure structural factor (loaded by ballast } \\
\text { and launch vehicle) }\end{array}$} & $1.5^{*}$ \\
\hline \multicolumn{2}{|c|}{ Design maximal wind speed in lower troposphere } & $18 \mathrm{~m} / \mathrm{s}$ \\
\hline \multicolumn{3}{|c|}{ * $10 \%$ margin for the ropes strength degradation included. } \\
\hline \multicolumn{3}{|c|}{ TABLE 3: Mass budget of the proposed LAS. } \\
\hline Component & Mass, kg & Fraction, $\%$ \\
\hline LVS rocket mass & 270 & 3.7 \\
\hline LVS aeroshell & 30 & 0.4 \\
\hline LVS-LAS attach points & 40 & 0.5 \\
\hline Traction cables & 1551 & 21.3 \\
\hline Clustering cable & 49 & 0.7 \\
\hline Top blocks & 91 & 1.2 \\
\hline Joints of traction cable & 670 & 9.2 \\
\hline Balloons, uninflated & 4566 & 62.6 \\
\hline Balloons avionics block & 25 & 0.3 \\
\hline Total & 7292 & 100.0 \\
\hline Balloons lift at $39.6 \mathrm{~km}$ & 8649 & 118.6 \\
\hline Ballast of balloons & 1357 & 18.6 \\
\hline
\end{tabular}

for the orbital launch. If 10000 launches of $7 \mathrm{~kg}$ payloads (70 tons total) within 30 years interval may be required for any realistic mission scenario, then the proposed LAS can be made cheap compared to the rocket LVS it propels. Also problem may be with the finding of the miniature high-performance rocket engine. For the proposed rocket an Ottobrunn $300 \mathrm{~N} \mathrm{LH2/LOX} \mathrm{thruster} \mathrm{with} \mathrm{the} \mathrm{specific}$ impulse $430 \mathrm{~s}$ and maximal thrust $500 \mathrm{~N}$ was selected for the preliminary simulation of the LVS. LH2/LOX is the best fuel for mass-produced LVS, if all considerations are taken into account [61]. It is not obvious whether the better engines will be developed; reference [62] has described the regress in the field of the liquid-fuel rocket engines design. Main problems described were failure to use the results from academic community in the engineering companies, failure of engineering companies to share or inherit design information, and many incompatible or proprietary software tools used for the rocket engines design. Small divisible payloads may be economically attractive [63], if associated penalties [64] are minimized (see Table 5).
TABLE 4: Life-cycle budget of the proposed LAS/LVS system.

\begin{tabular}{|c|c|c|}
\hline Component & Price, $\mathrm{k} \$$ & $\begin{array}{l}\text { Fraction, } \\
\quad \%\end{array}$ \\
\hline${ }^{\#}$ LVS rockets & 26.6 & 72.8 \\
\hline LVS aeroshell + attach points, 5 reuses & 1.3 & 3.6 \\
\hline Traction cable, 100 reuses & 3.4 & 9.3 \\
\hline *Balloons, 200 reuses (160 k\$/balloon [95]) & 0.8 & 2.2 \\
\hline $\begin{array}{l}\text { Traction motors cost, } 10000 \text { reuses }(10 \mathrm{hp} / \$) \\
{[12]}\end{array}$ & 0.17 & 4.3 \\
\hline Coupling cost, 10000 reuses & 0.08 & \\
\hline Variable frequency drivers, 10000 reuses & 0.08 & \\
\hline Line protection equipment, 10000 reuses & 0.02 & \\
\hline $\begin{array}{l}10 \mathrm{~km} \text { high-power transmission line, } 10000 \\
\text { reuses }\end{array}$ & 0.6 & \\
\hline Antisagging masts, 10000 reuses & 0.4 & \\
\hline Blocks cost, 1000 reuses & 0.1 & \\
\hline $\begin{array}{l}3 \mathrm{~km} \text { light railway for tension adjustment, } \\
10000 \text { reuses }\end{array}$ & 0.1 & \\
\hline $\begin{array}{l}\text { Technician salary, } 2 \text { men for } 30 \text { years ( } 10000 \\
\text { launches) }\end{array}$ & 3 & 8.2 \\
\hline Total cost per launch & 36.5 & 100 \\
\hline Cost per $\mathrm{kg}$ of payload to $\mathrm{LEO}, \mathrm{k} \$ / \mathrm{kg}$ & 5.2 & - \\
\hline
\end{tabular}

TABLe 5: Sources of the spending for the orbital assembly of the vehicles.

\begin{tabular}{|c|c|}
\hline$N$ & Factor \\
\hline 1 & Fuel efficiency of the interorbital transport \\
\hline 2 & $\begin{array}{l}\text { Maximal launch rate capability of earth-to-orbit } \\
\text { transport }\end{array}$ \\
\hline 3 & Assembly reliability \\
\hline 4 & Mass and utilization of the orbital support equipment \\
\hline
\end{tabular}

Although factor 2 may be not of the concern for the proposed LAS/LVS, factor 1 may be critical. The state of art of electric propulsion as in 1998 has lacked hall thrusters and ion thrusters with mass below $10 \mathrm{~kg}$ threshold [65], although no obvious physical limit exists for miniaturization. Reference [66] suggests whether the lack of small engines may be due to insufficient R\&D. In [67] the historical overview of the orbital launches statistics was provided, and no apparent upward trend was found; therefore the only way to reach an economic, high launch rate is the reduction of the unit payload mass. In [68] a trend was mentioned to use smaller, cheaper spacecrafts for the planetary exploration. Therefore, very small rocket LVS may be useful to increase the launch rate if divisible payloads will become common. Miniature LH2/LOX engine is the key for minimizing the liftoff weight and associated infrastructure, security and fly-away costs. To use the miniature LH2/LOX engine with the small fuel tanks, the interval between the leaving fuel topping facility and engine ignition (cable ride time) must be short. For proposed 
TABLE 6: NASA standard balloon sizes.

\begin{tabular}{|c|c|c|c|c|c|c|c|}
\hline Volume, $\mathrm{m}^{3}$ & $\begin{array}{c}\text { Balloon } \\
\text { weight, kg }\end{array}$ & $\begin{array}{l}\text { Suspended } \\
\text { weight, kg }\end{array}$ & $\begin{array}{c}\text { Equipment } \\
\text { weight, } \mathrm{kg}\end{array}$ & $\begin{array}{c}\text { Ballast weight for } \\
12 \mathrm{~h} \text { flight, } \mathrm{kg}\end{array}$ & $\begin{array}{l}\text { Ballast weight, } \mathrm{kg} \\
\text { for } 36 \mathrm{~h} \text { flight, } \mathrm{kg}\end{array}$ & $\begin{array}{c}\text { Nominal altitude, } \\
\mathrm{km}\end{array}$ & Sensitivity, $\mathrm{m} / \mathrm{kg}$ \\
\hline 328475 & 776 & 953 & 184 & 100 & 315 & 36.6 & 4.5 \\
\hline 328475 & 1461 & 2495 & 295 & 238 & 714 & 30.5 & 2.2 \\
\hline 659783 & 1701 & 1950 & 272 & 215 & 658 & 36.6 & 1.7 \\
\hline$* 804198$ & 1522 & 1361 & 227 & 170 & 522 & 39.6 & 2.2 \\
\hline 804198 & 2066 & 2495 & 295 & 272 & 828 & 36.6 & 1.8 \\
\hline
\end{tabular}

* Model selected for mass budget calculations.

LAS, maximal cable ride time may be derived from the selfpressurization equation for the LH2 tanks; these are most difficult to keep cool. For the most miniature $0.2 \mathrm{~m}$ diameter LH2 tanks with mediocre insulation $(100 \mathrm{~W} / \mathrm{m} 2)$, pressure rise $1 \mathrm{MPa}$ and 1-g conditions [69] give self-pressurization time of 7 minutes. LAS cable ride time below this limit is achievable with the $5.0 \mathrm{MW}$ minimal powers of traction motors combined in the proposed LAS configuration.

\section{Off-the-Shelf LAS Hardware}

The balloons suitable for use in the LAS prototypes are the NASA standard zero-pressure balloons. Balloons performance extracted from [70] is summarized in Table 6.

From Table 6 it is seen that even smallest NASA balloons can perform the desired LAS task, although at reduced altitude $30-33 \mathrm{~km}$. Medium-size and large balloons can easily boost the proposed LVS up to $36-39 \mathrm{~km}$ altitude.

For the tethers, only commercially available ropes (not single fibers) were evaluated. Carbon fibers can offer best performance in fibers, but in ropes its low notch resistance results in absence of long ropes. Carbon fibers also have an elevated electric conductivity. Electrically conductive fibers for the high-altitude ropes should be avoided because of the possibility to trigger a lightning propagating along the rope. Exhaust plume of rocket vehicle starting its engines near the top of the ropes may provide a conductive connection between the rope itself and surrounding air. Lightning triggered by launch vehicle exhaust plume is known phenomenon [71, 72] and was detected first during the launch of the Apollo-12. Another promising ropes material is the polyamide (Kevlar). In [73] the Kevlar cable was proposed to suspend geostationary satellite at half the geostationary altitude. Search for the commercially available Kevlar (or related poly-aramid ropes) did result in the ropes with maximal tip speed $1.7 \mathrm{~km} / \mathrm{s}$. But best tip speed can be achieved with the UHMWPE fibers. The material selected for the tethers was the SK-90 Dyneema rope with $3 \mathrm{~mm}$ diameter and with the UV-absorbing and antiabrasion coating [74]. The selected rope model has a maximal tip speed $2.07 \mathrm{~km} / \mathrm{s}$, including $10 \%$ strength margin to minimal breaking force. This is not the first proposal to use this material in tethers; authors of [11] have favored the selection of the UHMWPE fibers for the rotating space tethers and provided the 1.75-3.0 range of the engineering safety factor to implement a practical design. But authors in [11] have used mechanical data for the individual fibers, not the ropes. Selected structural factor of 1.5 for ropes corresponds to safety factor of 2.3 of individual SK-90 Dyneema fibers. But Dyneema drawback for the aerospace applications may be material (UHMWPE) susceptibility to the UV damage. Dyneema manufacturer never gave out the actual resistance of the Dyneema to the ultraviolet radiation. Empirical study [75] claims 3-year service life for 30\% tensile strength decrease of the Dyneema SK78 fiber on the sea level, which translates to 2000 hours of the solar irradiation at 90 degrees elevation angle. Reference [76] uses controlled solar imitator and concludes whether 200 hours of peak sea-level solar radiation are enough to cause $30 \%$ tensile strength degradation. Also, [76] points out the oxidation as the main pathway of the UV-related Dyneema degradation. Therefore, Dyneema photodegradation may be accelerated in the presence of ozone. The actual level of the ultraviolet radiation at $30-35 \mathrm{~km}$ altitude is also very variable and model dependent. Reference [77] mentions 50\% UV penetration for the wavelength range $205-300 \mathrm{~nm}$ at altitude $30-40 \mathrm{~km}$ with $30 \mathrm{~km}$ minimum at $205 \mathrm{~nm}$ wavelength, while light with wavelengths shorter than $200 \mathrm{~nm}$ (UV-C) is penetrating only to $40-60 \mathrm{~km}$ altitude, making protection from it largely irrelevant for the proposed design. The authors in [78] have observed synergy between UV-C radiation level and atomic oxygen erosion of polyethylene (and thus Spectra and Dyneema filaments). The polyethylene-derived products are degraded 10 times faster compared to polyimide (Kevlar), which have $22 \mathrm{mg} / \mathrm{g}$ baseline erosion rate divided by atomic oxygen flux. Therefore, long life of the Spectre or Dyneema ropes will be difficult to achieve in the LEO environment or high stratosphere. But both atomic oxygen and UV-C are absent below $40 \mathrm{~km}$ altitude, making protection from them not important for the balloons-anchored tethers. Reference [79] says the pure UHMWPE fibers are not absorbing any light with wavelengths above $190 \mathrm{~nm}$, but commonly processed grades have impurities absorbing light up to 270-330 nm wavelength. Therefore, the conclusion can be done whether the Dyneema rope strength degradation in stratosphere will be caused mostly by the UV light with 200 $300 \mathrm{~nm}$ wavelengths (UV-B). Simple model of the UV-B light level is the irradiation increase by $10-17 \%$ per each $\mathrm{km}$ of the altitude, given the $30 \%$ strength degradation time of Dyneema SK78 at $35 \mathrm{~km}$ as small as 0.8 hours. This estimate is only lower limit. Model uncertainty, geometric factor (low 
incident angle on the near-vertical ropes at times of the maximal UV flux), and usage of UV absorption coatings (as planned) should improve the lifetime of the rope. Rotation of the tether through blocks to spread UV damage, and lowering balloons a few kilometers than not in use, will improve rope lifetime hundreds to thousands hours.

\section{Conclusion}

The system-level design of the nonrocket LAS and rocket LVS for the ultralight payloads was proposed. System can deliver $7 \mathrm{~kg}$ to $\mathrm{LEO}$ with launch rate 1 launch per day. Estimated single launch full cost is 36400 USD and flyaway cost is 26600 USD, making the proposed system one of the cheapest launch systems in both launch price and price per payload mass category. The previously proposed applications for the similar LAS/LVS may be orbital fuel depot resupply, space station resupply, or Earth sensing. Among these, most researched was the interorbital tugs design. Cryogenic orbital storage [80, 81], transfer [82], operation model [83-85], and interorbital tugs designs [86-88] were elaborated. But [89, 90] was skeptical on feasibility of interorbital tugs. Supplying the Space Station with consumables and fuel may be easier, but this business segment is already taken. Therefore, the Earth sensing application may be also feasible. Reference [91] proposes a subkilogram satellite constellations, and [92] proposes swarms of subgram mass satellites on LEO for Earth sensing, and these can be easily deployed and replenished by the proposed LAS/LVS. The DARPA has also a requirement for the fast-reaction suborbital delivery, and Andrews Space Company proposes an hypersonic aircraftbased Peregrine/Falcon system [93] to fill this role. The proposed LAS/LVS may be technically and economically fit also for DARPA fast-reaction suborbital delivery. But because the proposed LAS/LVS is most suitable for orbital delivery of CubeSat-class satellites, some national space agency may choose to build described LAS/LVS to provide advanced service to the technology demonstration (or other purpose) CubeSat satellites manufacturers and therefore to improve a technological prowess of the respective country. The proposed launch scheme allows much more design, orbit and schedule flexibility for the technology demonstrators, effectively outcompeting current practice of riding CubeSats as secondary payloads in large commercial LVSs. The number of CubeSats produced in world per year is still too small (18 is planned in 2012) to fully utilize the launch rate potential of the proposed LAS, but it may rise if convenient LAS/LVS will become available.

\section{References}

[1] S. J. Isakowitz, J. B. Hopkins, and J. P. Hopkins Jr., International Reference Guide to Space Launch Systems, AIAA, 4th edition, 2004.

[2] HAAS Orbital Rocket Launcher (Brochure), ARCASPACE.

[3] R. M. Jones, "Electromagnetically launched microspacecraft for space science missions," AIAA Journal of Spacecraft and Rockets, vol. 26, no. 5, pp. 338-342, 1989.
[4] R. J. Glumb and H. Krier, "Concepts and status of Lasersupported rocket propulsion," AIAA Journal of Spacecraft and Rockets, vol. 21, no. 1, pp. 70-79, 1984.

[5] R. H. Frisbee et al., "Laser propulsion for the orbital transfer mission," AIAA Paper 85-1224, July 1985.

[6] L. Myrabo, "Record WSMR flight of beam-riding lightcraft propelled by high power laser ablation," AIAA Paper 20013798, July 2001.

[7] B. C. Edwards, "Design and deployment of a space elevator," Acta Astronautica, vol. 47, no. 10, pp. 735-744, 2000.

[8] N. M. Pugno, "On the strength of the carbon nanotube-based space elevator cable: from nanomechanics to megamechanics," Journal of Physics Condensed Matter, vol. 18, no. 33, article S14, pp. S1971-S1990, 2006.

[9] R. L. Forward, Indistinguishable from Magic, Baen Books, Riverdale, NY, USA, 1995.

[10] R. L. Forward, "Fail-safe multistrand tether structures for space propulsion," AIAA Paper 92-3214, July 1992.

[11] G. D. Nordley and R. L. Forward, "Mars-earth rapid interplanetary tether transport system: I. Initial feasibility analysis," AIAA Journal of Propulsion and Power, vol. 17, no. 3, pp. 499507, 2001.

[12] Motors Drives Price Book, 2009, http://www.tecowestinghouse.com.

[13] P. Williams and C. Blanksby, "Prolonged payload rendezvous using a tether actuator mass," AIAA Journal of Spacecraft and Rockets, vol. 41, no. 5, pp. 889-893, 2004.

[14] D. A. Tidman, "Constant-frequency hypervelocity slings," AIAA Journal of Propulsion and Power, vol. 19, no. 4, pp. 581587, 2003.

[15] G. R. Cooper, D. A. Tidman, and M. L. Bundy, "Numerical simulations of the slingatron," AIAA Journal of Propulsion and Power, vol. 18, no. 2, pp. 338-343, 2002.

[16] D. A. Tidman, "Slingatron mass launchers," AIAA Journal of Propulsion and Power, vol. 14, no. 4, pp. 537-544, 1998.

[17] D. A. Tidman, "Slingatron: a high velocity rapid fire sling," AIAA Journal of Propulsion and Power, vol. 18, no. 2, pp. 322329, 2002.

[18] M. L. Bundy, D. A. Tidman, and G. R. Cooper, "Sizing a slingatron-based space launcher," AIAA Journal of Propulsion and Power, vol. 18, no. 2, pp. 330-337, 2002.

[19] P. A. Penso and H. L. Mayer, "Tethers and asteroids for artificial gravity assist in the solar System," AIAA Journal of Spacecraft and Rockets, vol. 23, no. 1, pp. 79-82, 1986.

[20] L. A. Anderson and M. H. Haddock, "Tethered elevator design for space station," AIAA Journal of Spacecraft and Rockets, vol. 29, no. 2, pp. 233-238, 1992.

[21] R. P. Hoyt and C. Uphoff, "Cislunar tether transport system," AIAA Journal of Spacecraft and Rockets, vol. 37, no. 2, pp. 177186, 2000.

[22] E. L. M. Lanoix and A. K. Misra, "Near-earth asteroid missions using tether sling shot assist," AIAA Journal of Spacecraft and Rockets, vol. 37, no. 4, pp. 475-480, 2000.

[23] S. W. Ziegler and M. P. Cartmell, "Using motorized tethers for payload orbital transfer," AIAA Journal of Spacecraft and Rockets, vol. 38, no. 6, pp. 904-913, 2001.

[24] P. Williams, "Optimal control of tethered planetary capture missions," AIAA Journal of Spacecraft and Rockets, vol. 41, no. 2, pp. 315-319, 2004.

[25] P. Williams, C. Blanksby, and P. Trivailo, "Tethered planetary capture maneuvers," AIAA Journal of Spacecraft and Rockets, vol. 41, no. 4, pp. 603-613, 2004. 
[26] P. Williams, "Tether capture and momentum exchange from hyperbolic orbits," AIAA Journal of Spacecraft and Rockets, vol. 47, no. 1, pp. 205-209, 2010.

[27] M. D. Jokic and J. M. Longuski, "Design of tether sling for human transportation systems between Earth and Mars," AIAA Journal of Spacecraft and Rockets, vol. 41, no. 6, pp. 10101015, 2004.

[28] P. Williams, "Spacecraft rendezvous on small relative inclination orbits using tethers," AIAA Journal of Spacecraft and Rockets, vol. 42, no. 6, pp. 1047-1060, 2005.

[29] M. D. Jokic and J. M. Longuski, "Artificial gravity and abort scenarios via tethers for human missions to mars," AIAA Journal of Spacecraft and Rockets, vol. 42, no. 5, pp. 883-889, 2005.

[30] I. O. MacConochie, C. H. Eldred, and J. A. Martin, "Captureejector satellites," AIAA Journal of Spacecraft and Rockets, vol. 24, no. 4, pp. 289-290, 1987.

[31] J. R. Sanmartín and E. C. Lorenzini, "Exploration of outer planets using tethers for power and propulsion," AIAA Journal of Propulsion and Power, vol. 21, no. 3, pp. 573-576, 2005.

[32] D. Curreli, E. C. Lorenzini, C. Bombardelli et al., "Three-body dynamics and self-powering of an electrodynamic tether in a plasmasphere," AIAA Journal of Propulsion and Power, vol. 26, no. 3, pp. 385-393, 2010.

[33] P. Williams, "Simple approach to orbital control using spinning electrodynamic tethers," AIAA Journal of Spacecraft and Rockets, vol. 43, no. 1, pp. 253-256, 2006.

[34] J. M. Knapman, "High-altitude electromagnetic launcher feasibility," AIAA Journal of Propulsion and Power, vol. 22, no. 4, pp. 757-763, 2006.

[35] Estimating Capital Cost of Power Generating Plant Technologies (USD per kW), 2011, http://www.jcmiras.net/surge/ p130.htm

[36] E. Lantz, "Accelerators and decelerators for large hypersonic aircraft," AIAA Journal of Propulsion and Power, vol. 8, no. 3, pp. 539-540, 1992.

[37] L. D. Duncan and W. L. Vechione, "Vacuum-tube launchers and boosters," AIAA Journal of Spacecraft and Rockets, vol. 8, no. 6, pp. 679-681, 1971.

[38] E. Lantz, "High-energy launcher for commercial transportation to space," AIAA Journal of Spacecraft and Rockets, vol. 17, no. 3, pp. 163-164, 1980.

[39] R. B. Peterson, "Launch strategy using ground-based mass drivers," AIAA Journal of Spacecraft and Rockets, vol. 31, no. 5, pp. 912-914, 1994.

[40] B. B. Donahue, "Beating the rocket equation: air launch with advanced chemical propulsion," AIAA Journal of Spacecraft and Rockets, vol. 41, no. 2, pp. 302-309, 2004.

[41] N. Sarigul-Klijn, M. Sarigul-Klijn, and C. Noel, "Air-launching earth to orbit: effects of launch conditions and vehicle aerodynamics," AIAA Journal of Spacecraft and Rockets, vol. 42, no. 3, pp. 569-572, 2005.

[42] P. Hendrick, N. Heintz, D. Bizzarri, F. Romera, J. Murray, and P. Ngendakumana, "Air-hydrogen heat exchangers for advanced space launchers," AIAA Journal of Propulsion and Power, vol. 25, no. 6, pp. 1211-1219, 2009.

[43] V. V. Balepin, P. A. Czysz, and R. H. Moszée, "Combined engine for reusable launch vehicle (KLIN cycle)," AIAA Journal of Propulsion and Power, vol. 17, no. 6, pp. 1239-1246, 2001.

[44] R. Salkeld and R. S. Skulsky, "Air launch for space shuttles," Acta Astronautica, vol. 2, no. 7-8, pp. 703-713, 1975.

[45] S. Matsuda, H. Kanai, T. Fuji, M. Hinada, and M. Kaneoka, "Satellite launch concepts in Japan," in Proceedings of the 6th Responsive Space Conference (RS6 '08), vol. 5004, 2008.
[46] H. Shirasu, J. L. South, and J. A. Martin, "Analysis of concepts for single stage to orbit," AIAA Journal of Spacecraft and Rockets, vol. 33, no. 4, pp. 597-598, 1996.

[47] W. J. Bolster and G. C. Googins, "Design, development, and testing of a series of air-launched sounding rockets," AIAA Journal of Spacecraft, vol. 6, no. 4, pp. 460-465, 1969.

[48] M. Sarigul-Klijn, N. Sarigul-Klijn, B. Morgan et al., "Flight testing of a new earth-to-orbit air-launch method," Journal of Aircraft, vol. 43, no. 3, pp. 577-583, 2006.

[49] R. L. Burton, K. Brown, and A. Jacobi, "Low-cost launch of payloads to low Earth orbit," AIAA Journal of Spacecraft and Rockets, vol. 43, no. 3, pp. 696-698, 2006.

[50] S. Candel, "Concorde and the future of supersonic transport," AIAA Journal of Propulsion and Power, vol. 20, no. 1, pp. 59-68, 2004.

[51] J. R. Wertz, "Economic model of reusable vs. expendable launch vehicles," in Proceedings of the 51st IAF International Astronautical Congress, pp. 1-15, Rio de Janeiro, Brazil, October 2000.

[52] A. W. Wilhite, L. B. Bush, C. I. Cruz et al., "Advanced technologies for rocket single-stage-to-orbit vehicles," AIAA Journal of Spacecraft and Rockets, vol. 28, no. 6, pp. 646-651, 1991.

[53] F. W. Boltz, "Low-cost small-satellite delivery system," AIAA Journal of Spacecraft and Rockets, vol. 39, no. 5, pp. 818-820, 2002.

[54] C. Lambert, M. Nahon, D. Chalmers, and G. Gilardi, "Cable control of an aerostat platform: experimental results and model validation," Journal of Guidance, Control, and Dynamics, vol. 30, no. 2, pp. 620-628, 2007.

[55] R. M. Endlich, S. B. Solot, and H. A. Thur, "The mean vertical structure of the jet stream," Tellus, vol. 7, no. 3, pp. 308-313, 1955.

[56] E. V. Zaretsky, "Fatigue criterion to system design, life, and reliability," AIAA Journal of Propulsion and Power, vol. 3, no. 1, pp. 76-83.

[57] R. R. Rohrschneider and J. R. Olds, Development of a mass estimating relationship database for launch vehicle conceptual design, Graduation Report, Georgia Technology University, 2002.

[58] J. S. Knaur, "Is booster recovery and re-use practical?" AIAA Journal of Spacecraft, vol. 5, no. 4, pp. 488-490, 1968.

[59] H. Arend and H. Hermann Koellet, "Size and economics of big space freighters," AIAA Journal of Spacecraft and Rockets, vol. 26, no. 4, pp. 240-244, 1989.

[60] R. H. Miller, "The effect of demand on optimum launch vehicle size," AIAA Journal of Spacecraft and Rockets, vol. 16, no. 4, pp. 287-288, 1979.

[61] R. H. Frisbee, "Advanced space propulsion for the 21st century," AIAA Journal of Propulsion and Power, vol. 19, no. 6, pp. 1129-1154, 2003.

[62] G. P. Sutton, "History of liquid propellant rocket engines in the United States," AIAA Journal of Propulsion and Power, vol. 19, no. 6, pp. 978-1007, 2003.

[63] R. W. Allen, "Cost minimization of a space system by multiple launchings," AIAA Journal of Spacecraft, Engineering Notes, vol. 1, no. 1, pp. 112-113.

[64] H. Hermann Koelle, "Orbital burden rates for manned space missions," AIAA Journal of Spacecraft, vol. 1, no. 6, pp. 620625.

[65] R. L. Sackheim and D. C. Byers, "Status and issues related to in-space propulsion systems," AIAA Journal of Propulsion and Power, vol. 14, no. 5, pp. 669-675, 1998. 
[66] M. A. Turk and P. K. Zeiner, "Advanced technology payoffs for future small propulsion systems," AIAA Journal of Propulsion and Power, vol. 3, no. 4, pp. 313-319, 1987.

[67] I. S. Chang, "Overview of world space launches," AIAA Journal of Propulsion and Power, vol. 16, no. 5, pp. 853-866, 2000.

[68] R. Detwiler, S. Surampudi, P. Stella, K. Clark, and P. Bankston, "Designs and technologies for future planetary power systems," AIAA Journal of Propulsion and Power, vol. 12, no. 5, pp. 828-834, 1996.

[69] J. I. Hochstein, H. C. Ji, and J. C. Aydelott, "Prediction of selfpressurization rate of cryogenic propellant tankage," AIAA Journal of Propulsion and Power, vol. 6, no. 1, pp. 11-17, 1990.

[70] W. V. Jones, "Recent developments and near-term expectations for the NASA Balloon Program," AIAA Journal of Spacecraft and Rockets, vol. 27, no. 3, pp. 306-311, 1990.

[71] E. P. Krider, R. C. Noggle, M. A. Uman, and R. E. Orville, "Lightning and the apollo 17/saturn V exhaust plume," AIAA Journal of Spacecraft and Rockets, vol. 11, no. 2, pp. 72-75, 1974.

[72] W. J. Borucki, "Estimate of the probability of a lightning strike to the galileo probe," AIAA Journal of Spacecraft and Rockets, vol. 22, no. 2, pp. 220-221, 1985.

[73] V. A. Chobotov, "Synchronous satellite at less than synchronous altitude," AIAA Journal of Spacecraft, vol. 13, no. 3, pp. 126-128, 1976.

[74] New England Ropes, Model STS-12-90, February 2012, http:// www.neropes.com.

[75] E. McCorkle, R. Chou, D. Stenvers, P. Smeets, M. Vlasblom, and E. Grootendorst, "Fatigue and residual strength of fiber tuglines," in Proceedings of the MTS/IEEE Oceans Conference: Celabrating the Past... Teaming Toward the Future, pp. 10581063, San Diego, Calif, USA, September 2003.

[76] H. Zhang, M. Shi, J. Zhang, and S. Wang, "Effects of sunshine UV irradiation on the tensile properties and structure of ultrahigh molecular weight polyethylene fiber," Journal of Applied Polymer Science, vol. 89, no. 10, pp. 2757-2763, 2003.

[77] J. Lifland, "Solar variability and its effects on climate," Eos Transactions, American Geophysical Union, vol. 85, no. 30, p. 284, 2004.

[78] K. Yokota and M. Tagawa, "Comparison of polyethylene and polyimide as a fluence monitor of atomic oxygen," AIAA Journal of Spacecraft and Rockets, vol. 44, no. 2, pp. 434-438, 2007.

[79] J. F. Rabek, Photodegradation of Polymers: Physical Characteristics and Applications, Springer, Berlin, Germany, 1996.

[80] J. D. Schweikle, G. O. Fredrickson, and P. L. Klevatt, "Orbital experimentation for advancing cryogenic technology," AIAA Journal of Spacecraft, vol. 6, no. 3, pp. 259-263, 1969.

[81] J. L. Thurman and E. H. Ingram, "Application of heat pipes to reduce cryogenic boiloff in space," AIAA Journal of Spacecraft and Rockets, vol. 6, no. 3, pp. 319-321, 1969.

[82] J. E. Boretz, "Orbital refueling techniques," AIAA Journal of Spacecraft and Rockets, vol. 7, no. 5, pp. 513-522, 1970.

[83] W. Frank Staylor, D. R. Brooks, and E. Brian Pritchardi, "Requirements and capabilities of interorbital shuttles," AIAA Journal of Spacecraft and Rockets, vol. 7, no. 7, pp. 513-522, 1970.

[84] G. T. Kroncke, "Benefits of a reusable upper stage orbital maneuvering vehicle," AIAA Journal of Spacecraft and Rockets, vol. 22, no. 3, pp. 351-354, 1985.

[85] A. M. Long, M. G. Richards, and D. E. Hastings, "On-orbit servicing: a new value proposition for satellite design and operation," AIAA Journal of Spacecraft and Rockets, vol. 44, no. 4, pp. 964-976, 2007.
[86] I. O. MacConochie, J. J. Rehder, and E. P. Brien, "Preliminary design for a space-based orbital transfer vehicle," AIAA Journal of Spacecraft and Rockets, vol. 17, no. 3, pp. 256-259, 1980.

[87] L. D. Jaffe, "Nuclear-electric reusable orbital transfer vehicle," AIAA Journal of Spacecraft and Rockets, vol. 25, no. 5, pp. 375$381,1988$.

[88] J. Hermel, R. A. Meese, W. P. Rogers, R. O. Kushida, J. R. Beattie, and J. Hyman, "Modular, ion-propelled, orbit-transfer vehicle," AIAA Journal of Spacecraft and Rockets, vol. 25, no. 5, pp. 368-374, 1988.

[89] J. D. Mason, "Space tug performance optimization," AIAA Journal of Spacecraft, vol. 9, no. 7, pp. 491-492, 1972.

[90] E. L. Strauss, "Ablative thermal protection for space tug multipass, aerobraking entry," AIAA Journal of Spacecraft and Rockets, vol. 12, no. 6, pp. 346-350, 1975.

[91] D. J. Bamhart, T. Vladimirova, and M. N. Sweeting, "Satellite miniaturization techniques for space sensor networks," AIAA Journal of Spacecraft and Rockets, vol. 46, no. 2, pp. 469-472, 2009.

[92] M. Peck, "Chips in space: how satellites the size of chips could revolutionize the way we explore space," IEEE Spectrum, vol. 48 , no. 8, pp. 42-47, 2011.

[93] Andrews et al., "A new vision for operationally responsive space and force projection," in Proceedings of the Reinventing Space Conference (RS '12), May 2012, http://www.responsivespace.com/Papers/RS2/FALCON/Andrews\%20RS2.pdf.

[94] F. W. Boltz, "Optimal Ascent Trajectory for Efficient Air Launch into Orbit," AIAA Journal of Spacecraft and Rockets, vol. 41, no. 1, pp. 153-157, 2004.

[95] M. S. Smith and G. Allison, "The return of the Balloon as an Aerospace Test Platform," Raven Aerospace Brochure, 1999.

[96] K. E. French, "Ascent trajectory of a superpressure balloon," AIAA Journal of Spacecraft, vol. 4, no. 11, pp. 1557-1559, 1967.

[97] C. H. Jenkins and W. W. Schur, "Gore/seam architectures for gossamer structures," AIAA Journal of Spacecraft and Rockets, vol. 39, no. 5, pp. 669-673, 2002.

[98] Spacecraft/Vehicle Level Cost Model, 2011, http://cost.jsc.nasa .gov/SVLCM.html. 

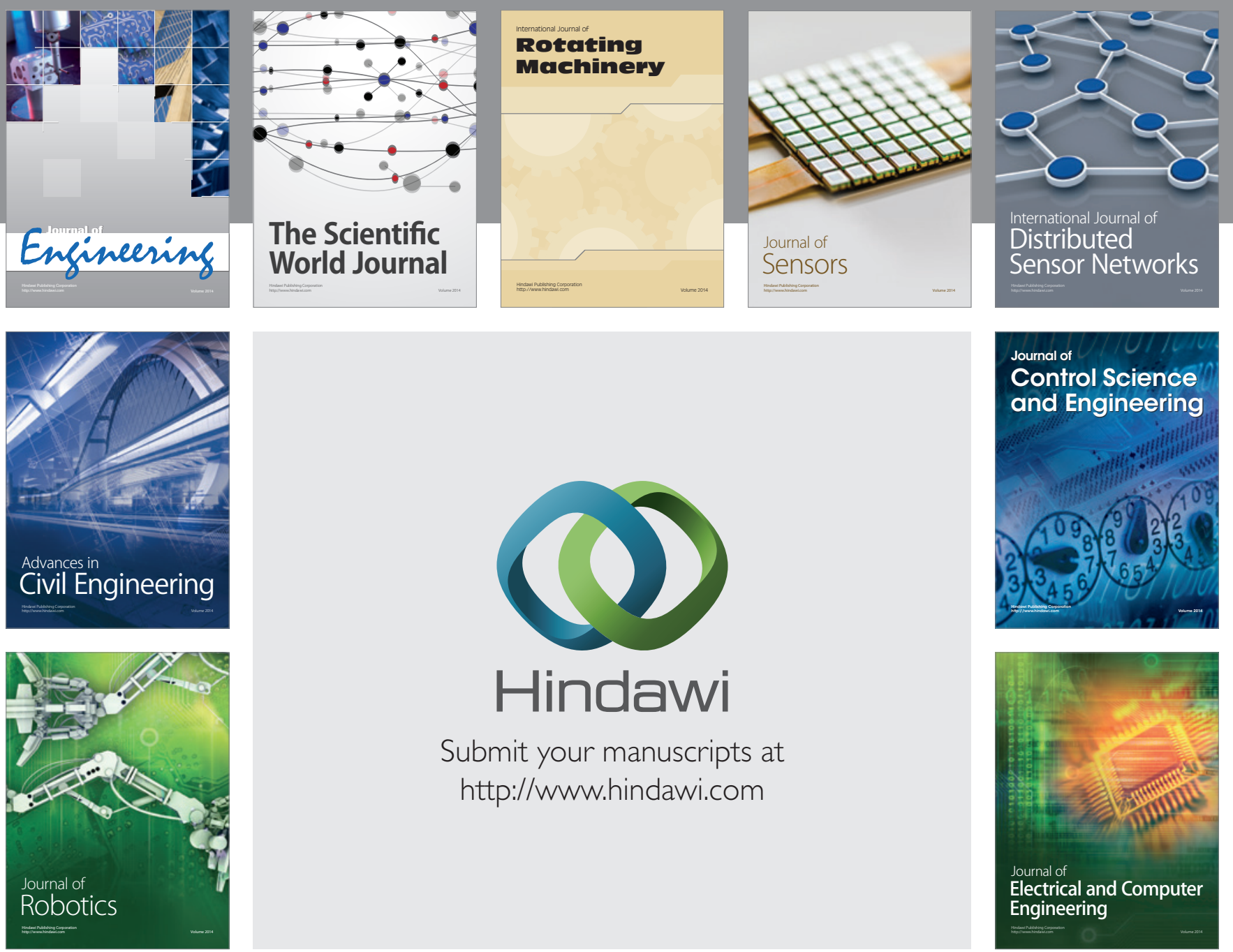

Submit your manuscripts at

http://www.hindawi.com
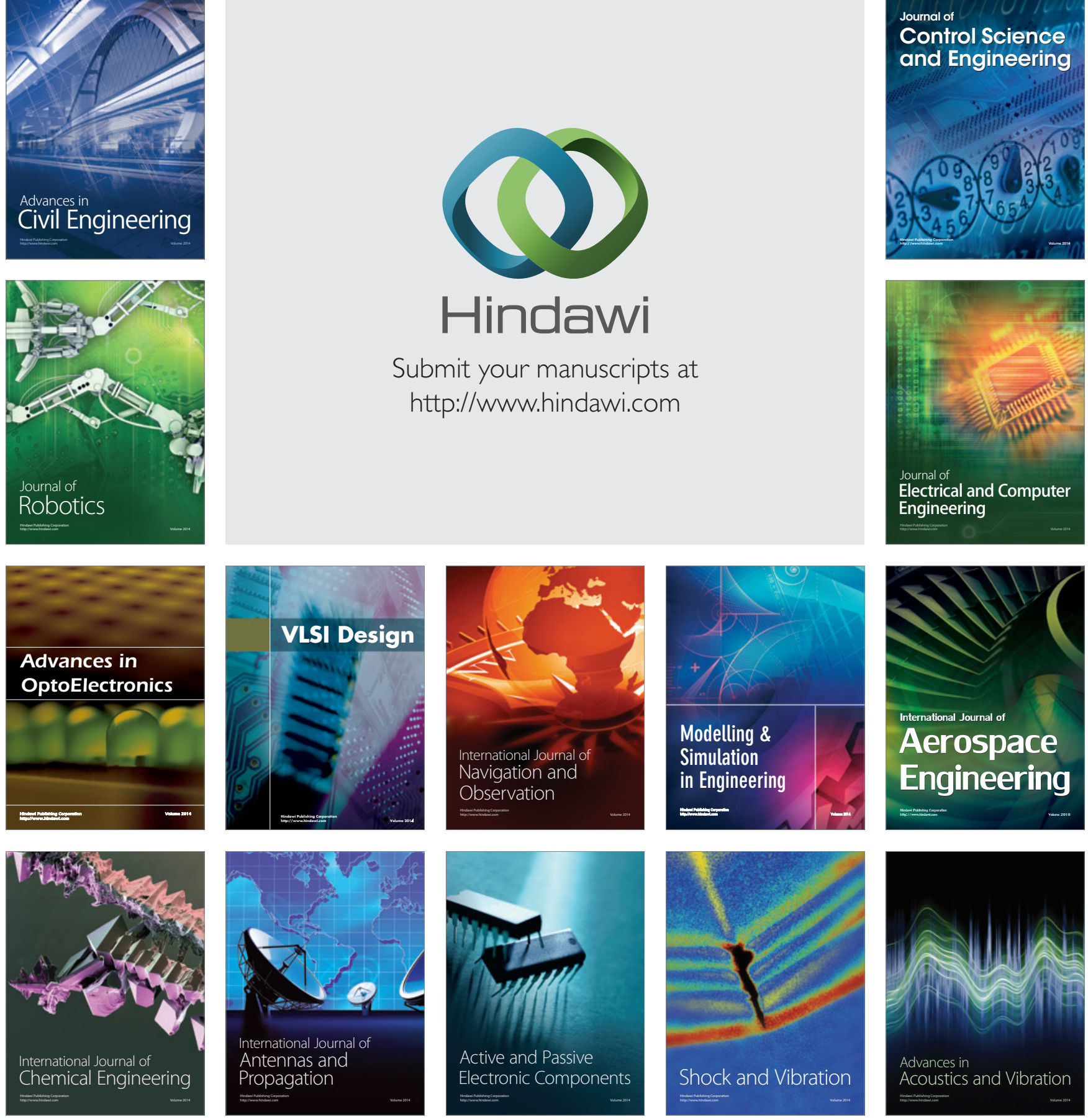